\title{
Role of Iron in Rhizobacteria-Mediated Induced Systemic Resistance of Cucumber
}

\author{
C. M. Press, J. E. Loper, and J. W. Kloepper
}

First author: Department of Botany and Plant Pathology, Oregon State University, Corvallis 97331; second author: Horticulture Crops Research Lab, USDA-ARS, Corvallis, OR 97330; and third author: Department of Entomology and Plant Pathology, Auburn University, AL 36849.

Accepted for publication 16 March 2001.

\section{ABSTRACT}

Press, C. M., Loper, J. E., and Kloepper, J. W. 2001. Role of iron in rhizobacteria-mediated induced systemic resistance of cucumber. Phytopathology 91:593-598.

Seed treatment with the rhizosphere bacterium Serratia marcescens strain 90-166 suppressed anthracnose of cucumber, caused by Colletotrichum orbiculare, through induced systemic resistance (ISR). When the iron concentration of a planting mix was decreased by addition of an iron chelator, suppression of cucumber anthracnose by strain $90-166$ was significantly improved. Strain $90-166$ produced $465 \pm 70 \mathrm{mg} / \mathrm{liter}$ of catechol siderophore, as determined by the Rioux assay in deferrated King's medium B. The hypothesis that a catechol siderophore produced by strain 90-166 may be responsible for induction of systemic resistance by this strain was tested by evaluating disease suppression by a miniTn5-phoA mutant deficient in siderophore production. Sequence analysis of genomic DNA flanking the mini-Tn5-phoA insertion identified the target gene as $e n t A$, which encodes an enzyme in the catechol siderophore biosynthetic pathways of several bacteria. Severity of anthracnose of cucumbers treated with the entA mutant was not significantly different $(P=0.05)$ from the control, whereas plants treated with wild-type 90-166 had significantly less disease $(P=0.05)$ than the control. Total (internal and external) population sizes of 90-166 and the entA mutant on roots did not differ significantly $(P=0.05)$ at any sample time, whereas internal population sizes of the entA mutant were significantly lower $(P=0.05)$ than those of the wild-type strain at two sampling times. These data suggest that catechol siderophore biosynthesis genes in Serratia marcescens 90-166 are associated with ISR but that this role may be indirect via a reduction in internal root populations.

Additional keywords: systemic acquired resistance.
Certain strains of rhizosphere bacteria can suppress plant diseases by inducing resistance responses in the plant through a process termed induced systemic resistance (ISR) $(3,46,48)$. The mechanisms involved in ISR are just beginning to be elucidated $(10,14$, $22,23,28,33,34)$, and appear to vary among bacterial strains and pathosystems. In at least some systems, however, ISR is influenced by iron availability. For example, we previously reported that ISR induced by Serratia marcescens strain 90-166 against cucumber anthracnose is reduced when iron is made more available in the planting medium (34). Similarly, Leeman et al. (22) reported that ISR induced by Pseudomonas fluorescens WCS374 against Fusarium wilt of radish is inversely related to iron availability of the planting substrate. Furthermore, the production of at least two bacterial metabolites with proposed roles in ISR are inversely regulated by iron. Several strains of rhizosphere bacteria produce salicylic acid (SA) $(14,22,28,34)$ in environments in which iron is not plentiful, and SA contributes to ISR mediated by a subset of the strains that produce it. The vast majority of microorganisms produce siderophores $(6,49)$, a diverse class of high-affinity iron chelating compounds that are produced in response to iron limitation, and exported from the cell where they chelate ferric iron. Ferric-siderophore complexes are recognized and bound by specific outer-membrane receptor proteins, and iron is transported into the cell where it becomes available for metabolic functions. Among the siderophores produced by rhizo-

Corresponding author: C. M. Press; E-mail address: pressc@ava.bcc.orst.edu

Publication no. P-2001-0402-01R

This article is in the public domain and not copyrightable. It may be freely reprinted with customary crediting of the source. The American Phytopathological Society, 2001. sphere bacteria, only the pyoverdines (also called pseudobactins) produced by the fluorescent pseudomonads have been implicated in ISR $(15,28)$.

The rhizosphere bacterium Serratia marcescens 90-166 can induce resistance to plant disease caused by $P$. syringae pv. lachrymans, Colletotrichum orbiculare, and Erwinia tracheiphila in a field environment (34). Because the capacity of 90-166 to induce resistance is diminished under iron-replete conditions (34), we are investigating the contribution of iron-regulated metabolites produced by the bacterium to ISR. We previously demonstrated that SA had a minor role in ISR induced by $90-166$; three mutants of 90-166 lacking SA production retained the capacity to induce resistance of cucumber against anthracnose caused by the pathogen $C$. orbiculare (34). We also described a mutant of 90-166 that is deficient in the production of a siderophore and in ISR (34). The siderophore produced by 90-166 has not been identified, but other strains of Serratia marcescens produce the catechol siderophore enterobactin $(4,52)$. Like other catechol siderophores produced by members of the Enterobacteriaceae, enterobactin is derived from chorismate via isochorismate and dihydroxybenzoic acid (DHBA; Sigma Chemical, St. Louis) (1,16,25-27,29,36, 37,41,50). Enzymes encoded by ent $C$, entB, and entA (or their homologs in other bacterial species) catalyze the formation of DHBA from chorismate $(1,16,25-27,29,36,37,41,50)$ and a multienzyme complex composed of the products of entD, entE, entF, and ent $G$ catalyzes the synthesis of enterobactin from three molecules each of DHBA and serine $(30,38,39)$. In pseudomonads, SA is produced from chorismate and isochorismate via PchB (43). It is unknown if the same pathway is utilized by Serratia marcescens to produce SA, but there may be a link between SA and siderophore production. The objectives of this study were to (i) characterize the siderophore-deficient mutant of 
90-166, (ii) evaluate the siderophore-deficient mutant for disease suppression via ISR and root colonization, and (iii) further investigate the relationship between iron availability and ISR induced by $90-166$.

\section{MATERIALS AND METHODS}

Bacterial strains. Serratia marcescens strain 90-166 was used for all experiments. This strain has intrinsic resistance to tetracycline and ampicillin at 100 and $500 \mu \mathrm{g} / \mathrm{ml}$, respectively, and produces $\mathrm{SA}$ at $2.89 \pm 0.95 \mu \mathrm{g} / \mathrm{ml}$ in stationary phase cultures grown in King's Medium B (KMB). Serratia marcescens 90-166-2882 (34) is a mini-Tn5-phoA insertion mutant of 90-166 selected for lack of siderophore production on the universal siderophore detection medium containing chrome azurol S (42). Mutant 90-166-2882 produces SA at $1.86 \pm 0.63 \mu \mathrm{g} / \mathrm{ml}$ (34). All other strains used are described in Table 1.

Quantification of catechol siderophore production. Catechol production was quantified according to the colorimetric assay described by Rioux et al. (35). Test strains were grown in either minimal medium Davis (MMD; Difco Laboratories, Detroit) broth amended with succinate $(15 \mathrm{mM})$ and $1 \mathrm{~g} /$ liter of ammonium sulfate (MMDN) or deferrated $\mathrm{KMB}$ broth for $48 \mathrm{~h}$ at $25^{\circ} \mathrm{C}$ with shaking $(200 \mathrm{rpm})$. Deferration of media was accomplished by serial extraction of KMB (adjusted to $\mathrm{pH}$ 9.0) with chloroform plus (1\%, wt/vol) 8-hydroxyquinoline (Sigma) in a separatory funnel (6). KMB was extracted until the green coloration of the chloroform layer was no longer evident. Residual 8-hydroxyquinoline was removed by extraction with chloroform at $\mathrm{pH} 9.0$ and 7.0, respectively. Mini-Tn5-phoA mutants were grown in MMDN amended with $50 \mu \mathrm{g} / \mathrm{ml}$ of kanamycin and $100 \mu \mathrm{g} / \mathrm{ml}$ of tetracycline. Cultures were centrifuged, and supernatants were filtered to remove bacterial cells. DHBA was used to set a standard curve for quantification of catechol siderophore production using a spectrophotometer $(\lambda=510 \mathrm{~nm}$ ) (detection limit $4 \mathrm{mg} / \mathrm{liter}$ ). Controls included either broth and water in place of culture supernatant, or water in place of 1,10-phenanthroline solution (35). 1,10-Phenanthroline is necessary for the colorimetric reaction in the Rioux assay, and replacing this component with water generates a negative control for the reaction (35).

TABLE 1. Bacterial strains and plasmids ${ }^{\mathrm{z}}$

\begin{tabular}{|c|c|c|}
\hline Species and strain & Description & Source \\
\hline \multicolumn{3}{|l|}{ Escherichia } \\
\hline E. coli AN93 & $\begin{array}{l}\text { entE405, fluA derivative of } \\
\text { AN194(20) }\end{array}$ & (31) \\
\hline E. coli AN193 & entA403, fhuA & (47) \\
\hline E. coli $\mathrm{DH} 5 \alpha$ & $\begin{array}{c}\left.F^{-} \text {endA1 hsdR17( } \mathrm{r}_{\mathrm{K}}^{-} \mathrm{m}_{\mathrm{K}}^{+}\right) \text {supE44 } \\
\text { thi-1 recA1 gyrA96 relA1 } \\
\phi 80 \text { dlacZ M15 } \lambda^{-}\end{array}$ & $(24,51)$ \\
\hline E. coli $\mathrm{K} 12$ & thi-1, thr, leu, tonA, lacY, supE & ATCC25290 \\
\hline E. coli SM10 $\lambda$ pir & recA::RP4-2-Tc::Mu, $\lambda$ pir & (13) \\
\hline E. coli XL1-BlueMR & $\begin{array}{l}\Delta(m c r A) 183 \Delta(\text { mcrCB-hsdSMR- } \\
\text { mrr }) 173 \text { endA1 supE44 thi-1 } \\
\text { recA1 gyrA96 relA1 lac }\end{array}$ & Stratagene \\
\hline \multicolumn{3}{|l|}{ Pseudomonas } \\
\hline $\begin{array}{l}\text { P. fluorescens 89B-61 } \\
\text { Salmonella }\end{array}$ & Field isolate & J. W. Kloepper \\
\hline S. typhimurium enb1 & $\mathrm{Ent}^{-} \mathrm{Sm}^{\mathrm{R}}$ & (32) \\
\hline S. typhimurium enb7 & Ent $^{-} \mathrm{DHBA}^{-} \mathrm{Sm}^{\mathrm{R}}$ & (32) \\
\hline \multicolumn{3}{|l|}{ Serratia } \\
\hline S. marcescens $90-166$ & $\mathrm{Tc}^{\mathrm{R}}, \mathrm{Ap}^{\mathrm{R}}$ (intrinsic) & J. W. Kloepper \\
\hline $\begin{array}{l}\text { S. marcescens } \\
\quad 90-166-2882\end{array}$ & $\begin{array}{c}\text { ent } A: \text { :mini-Tn5-phoA derivative of } \\
90-166, \mathrm{Tc}^{\mathrm{R}}, \mathrm{Ap}^{\mathrm{R}}, \mathrm{Km}^{\mathrm{R}}, \mathrm{Cat}^{-}\end{array}$ & C. M. Press \\
\hline \multicolumn{3}{|l|}{ Plasmids } \\
\hline pUT mini-Tn5-phoA & $\mathrm{Ap}^{\mathrm{R}} \mathrm{Km}^{\mathrm{R}}$; derived from $\mathrm{pGP} 704$ & (13) \\
\hline SuperCos 1 & $\mathrm{Ap}^{\mathrm{R}} \mathrm{Km}^{\mathrm{R}}$ & Stratagene \\
\hline
\end{tabular}

Cross-feeding of siderophore-deficient strains. Strains 90-166 and 90-166-2882 were tested in assays using Escherichia coli (21) and Salmonella typhimurium (32) with mutations in specific enterobactin biosynthesis genes as indicator strains (9). The Ent ${ }^{-}$ (enb-1, AN93) or $\mathrm{DHBA}^{-}$(enb-7, AN193) strains cannot produce the siderophore but can utilize iron in the ferric-enterobactin complex. The indicator strains will grow on iron-deficient medium only in the presence of siderophores that are recognized by the receptor for ferric-enterobactin in the bacterial outer membrane. Therefore, the growth of indicator strains can be induced only by siderophores with functional similarity to enterobactin. Indicator strains were grown overnight in Tris minimal salts (TMS) broth (44) supplemented with tryptophan $(0.003 \%$, wt $/ \mathrm{vol})$, thiamine $(0.0002 \%$, wt/vol), deferrated Casamino acids $(0.3 \%$, wt/vol), $\mathrm{FeCl}_{3}(0.1 \mu \mathrm{M})$, and streptomycin $(100 \mu \mathrm{g} / \mathrm{ml})$. All chemicals were purchased from Sigma Chemical. TMS agar amended with $150 \mu \mathrm{M} 2,2^{\prime}$-dipyridyl was seeded with $10^{5} \mathrm{CFU} / \mathrm{ml}$ of the indicator strains. Test strains were spotted onto seeded, solidified TMS medium, and the plates were incubated for 24 to $48 \mathrm{~h}$ at $28^{\circ} \mathrm{C}$. After incubation, plates were examined for growth of the indicator strains surrounding colonies producing siderophores with functional similarity to enterobactin. P. fluorescens strain 89B-61 and Escherichia coli strain K12 were included to provide negative and positive controls, respectively.

Cucumber ISR assays. Strains 90-166 and 90-166-2882 were compared to determine if siderophore production was involved in induction of systemic disease resistance in cucumber. Strains were grown in either $\mathrm{KMB}$ or $\mathrm{KMB}$ amended with $50 \mu \mathrm{g} / \mathrm{ml}$ of kanamycin and $100 \mu \mathrm{g} / \mathrm{ml}$ of tetracycline, respectively, for $48 \mathrm{~h}$ at $25^{\circ} \mathrm{C}$ with shaking at $200 \mathrm{rpm}$. Strains were centrifuged and resuspended in physiological saline $(0.14 \mathrm{M} \mathrm{NaCl})$. Cucumber seeds (cv. SMR58) were either soaked in bacterial suspensions or saline for $30 \mathrm{~min}$, and planted in pots containing Promix (Premier Peat, Rivière-du-Loup, Quebec). Seeds were covered, and pots were placed on a greenhouse bench for the duration of the experiment. Plants were fertilized with 15-16-17 (N-P-K; Peter's Professional, The Scott's Co., Marysville, OH; $2.5 \mathrm{~g} / \mathrm{liter}$ ) at 14 days after planting (DAP) and were challenged with the pathogen, $C$. orbiculare, at 28 DAP. Conidial suspensions of $C$. orbiculare were maintained in $50 \%$ glycerol $(\mathrm{vol} / \mathrm{vol})$ at $-80^{\circ} \mathrm{C}$ for long-term storage. $C$. orbiculare was cultured by spread-plating a conidial suspension on green bean agar plates (17), incubating plates for 7 days at $28^{\circ} \mathrm{C}$, and suspending conidia in water $\left(10^{5}\right.$ conidia per $\mathrm{ml}$ ). Plants were sprayed to runoff, placed in a humidity chamber for $24 \mathrm{~h}$ to facilitate infection, and returned to the greenhouse bench. Pots were arranged in a randomized complete block design (RCBD) with 10 replications. Control treatments included nonbacterized (disease) control and a pathogen-induced (positive) control. For the positive control, cucumbers were induced with the pathogen at the cotyledon stage by pricking the underside of the cotyledon with a pipette tip and inoculating the wounds with $10^{6}$ conidia per $\mathrm{ml}$. For these experiments, each leaf of each plant was rated according to the disease rating scale of Thompson and Jenkins (45), where $1=0$ to $1 \%$ infected leaf area, $2=1$ to $3 \%$, $3=3$ to $6 \%, 4=6$ to $12 \%, 5=12$ to $25 \%, 6=25$ to $50 \%, 7=$ 50 to $75 \%$, and $8=75$ to $100 \%$ of the leaf being infected. Rates were averaged for each plant, and treatment differences were compared using single-degree-of-freedom contrasts with SAS and JMP software (SAS Institute, Cary, NC). Experiments were repeated at least four times.

Experiments were designed to determine if lowered iron concentrations in the potting medium influenced ISR. Cucumber plants were treated biweekly with $10 \mu \mathrm{M}$ ethylenediamine di(ohydroxyphenylacetic acid) (EDDHA) solution as a root drench. Fe-EDDHA has a formation constant of $\mathrm{K}^{33.9}$ and decreases iron available to bacteria in soil. The experiment was a $3 \times 2$ factorial arranged as a RCBD. Factors were three levels of cucumber treatment (no treatment [disease control], pathogen-induced [ISR con- 
trol], and bacterial treatment [90-166]) and two levels of EDDHA treatment $(0$ and $10 \mu \mathrm{M})$. All other aspects of the experiment were described previously.

Root colonization assays. Strains 90-166 and 90-166-2882 were evaluated for total (internal and external) and internal root colonization of cucumber. The cucumber assay was as described previously, except seeds were planted in a 2:1 mixture of sand/ clay. The experiment was a $2 \times 5$ factorial arranged in a RCBD with seven replications. In order to determine the total root population sizes, the following were used: two levels of bacterial treatment (90-166 or 90-166-2882) and six levels of sampling time $(0,1,4,7$, and $21 \mathrm{DAP})$. In order to determine the internal root population sizes, roots were harvested at 4,8 , and $10 \mathrm{DAP}$, rinsed under running water to remove the potting medium, and weighed. Total root population sizes were determined by triturating roots in $0.02 \mathrm{M}$ phosphate buffer $(\mathrm{pH} 7)$ and plating on tryptic soy agar amended with either $100 \mu \mathrm{g} / \mathrm{ml}$ of ampicillin (for 90-166) or ampicillin and $50 \mu \mathrm{g} / \mathrm{ml}$ of kanamycin (for 90-166-2882). Internal root population sizes were determined after surface-disinfesting roots for $1 \mathrm{~min}$ in $30 \%$ hydrogen peroxide and $1 \mathrm{~min}$ in $1.05 \%$ sodium hypochlorite $(\mathrm{pH}$ 10.4) followed by five rinses in sterile distilled water. Roots were treated subsequently as previously described for total root population determinations. All other aspects of the experiment were completed as described previously, and the experiment was repeated three times.

Southern analysis. Total genomic DNA of 90-166 or 90-1662882 was isolated by the cetyltrimethylammoniumbromide (CTAB) method (5), digested with BamHI (Gibco BRL Life Technologies, Gaithersburg, MD), and restriction fragments were separated by agarose gel electrophoresis. DNA was transferred from agarose gels to Nytran filters according to the manufacturer's directions (Schleicher and Schuell, Keene, NH). pUT-mini-Tn5-phoA (13), used as a probe, was labeled with biotinylated dATP by nicktranslation (Blue-Gene Kit; Gibco BRL Life Technologies) and purified with a D50 column (International Biotechnologies Inc., New Haven, CT). Blots were visualized according to the manufacturer's directions.

Genetic analysis of the region surrounding Tn5-phoA insertion. A 4.8-kb Bam HI fragment containing the mini-Tn5phoA and $1.3 \mathrm{~kb}$ of genomic DNA flanking the insertion site was cloned into pUC19 and transformed into Escherichia coli DH5 $\alpha$ $(24,40)$. Transformants were selected based on kanamycin resistance conferred by mini-Tn5-phoA. The genomic DNA flanking the transposon insertion site was sequenced with primers complementary to pUC19 sequences flanking the cloning site. DNA sequencing was conducted by the Center for Gene Research and Biotechnology (Oregon State University, Corvallis). Subsequent sequencing was performed with primers designed from previous sequence determinations. A contiguous sequence was compiled using the SeqLab software program (version 10, Genetics Computer Group, Madison, WI). DNA sequence results were compared with known sequences in the GenBank and EMBL databases using BLAST (National Center for Biotechnology Information, National Library of Medicine, Bethesda, MD). The accession number of the nucleotide sequence of the entC-entA region of Serratia marcescens $90-166$ is AF358745.

Genomic library preparation. A genomic library of DNA fragments from 90-166 was created using a cosmid vector kit (SuperCos1; Stratagene, La Jolla, CA). Total genomic DNA of 90-166 was extracted and partially digested with Sau3AI. Resulting fragments were dephosphorylated, ligated into SuperCos 1 DNA, and packaged into Escherichia coli XL1-Blue MR using the Gigapack III Gold packaging extract (Stratagene) according to manufacturer's directions. Cosmid clones were screened by colony hybridization with a 400-bp polymerase chain reaction amplification product of the entA homolog adjacent to the mini-Tn5phoA insertion of 90-166-2882 as a probe. One of three colonies that hybridized to the probe was subjected to Southern analysis, and a 2.0-kb Pst I-EcoRI restriction fragment hybridizing to the entA probe was cloned into pUC19 and sequenced.

\section{RESULTS}

The effect of low iron concentration on bacterial-mediated ISR. To characterize the effect of iron concentration on 90-166mediated ISR, iron concentration of the planting mix was decreased by addition of an iron chelator. Root drenches with $10 \mu \mathrm{M}$ EDDHA applied every 4 days did not suppress cucumber anthracnose nor did they enhance ISR achieved by pre-inoculation with pathogen $C$. orbiculare (Table 2). In association with the 90-166 seed treatment, however, EDDHA root drenches significantly decreased disease $(P=0.05)$ compared with $90-166$ treatment alone.

Siderophore determination. Strain 90-166 produced $101 \pm$ $43 \mathrm{mg} / \mathrm{liter}$ of catechol siderophores in MMDN and $465 \pm$ $70 \mathrm{mg} /$ liter in deferrated KMB after $48 \mathrm{~h}$. Lower catechol siderophore production in MMDN was attributed in part to the reduced growth of strain 90-166 in this medium than in deferrated KMB. Strain 90-166-2882, a mini-Tn5-phoA insertion mutant of 90-166, did not produce detectable catechol siderophores in MMDN or deferrated KMB as determined by the Rioux assay.

Cross-feeding of siderophore-deficient strains. Ent ${ }^{-}(e n b-1$, AN93) and DHBA- (enb-7, AN193), indicator strains of Salmonella typhimurium and Escherichia coli, were used to detect siderophore production by $90-166$. Wild-type strain $90-166$ induced growth of all the indicator strains, suggesting that 90-166 produces a siderophore with functional similarity to enterobactin. The $\mathrm{Cat}^{-}$derivative 90-166-2882 did not induce growth of any of the indicator strains, suggesting that the transposon insertion disrupted a gene required for production of DHBA.

Genetic analysis of the Cat $^{-}$mutant. Southern analysis detected mini-Tn5-phoA on a single 4.8-kb BamHI fragment in the genome of 90-166-2882, indicating that the catechol-deficient mutant has a single transposon insertion. The BamHI fragment was cloned and DNA flanking the mini-Tn5-phoA insertion was sequenced. The nucleotide sequence of $176 \mathrm{bp}$, adjacent to the transposon insertion, was $71 \%$ identical to nucleotides $1665-1841$ of entA of Escherichia coli, which encodes 2,3-dihydro-2,3dihydroxybenzoate dehydrogenase, an enzyme in the enterobactin

TABLE 2. The role of iron on induced systemic resistance (ISR) mediated by Serratia marcescens strain 90-166 against anthracnose of cucumber caused by Colletotrichum orbiculare

\begin{tabular}{lcc}
\hline & \multicolumn{2}{c}{ Mean disease rating $^{\mathrm{x}}$} \\
\cline { 2 - 3 } Treatment $^{\mathrm{w}}$ & Ambient iron availability & Low iron availability $^{\mathrm{z}}$ \\
\hline Nonbacterized & $8.00 \mathrm{a}$ & $7.89 \mathrm{a}$ \\
SAR control & $6.75 \mathrm{~d}$ & $6.85 \mathrm{~d}$ \\
Serratia marcescens & $7.60 \mathrm{~b}$ & $7.25 \mathrm{c}$ \\
$\quad$ & & \\
\hline
\end{tabular}

${ }^{w}$ Cucumber seeds were soaked in $0.14 \mathrm{M} \mathrm{NaCl}$ (nonbacterized [disease] control and systemic acquired resistance (SAR) [pathogen-induced] control), or bacterial suspensions $(10 \log \mathrm{CFU} / \mathrm{ml})$. The experiment was a $3 \times 2$ factorial (three bacterization levels: disease, pathogen-induced control, and 90-166) and two iron levels (0 and $10 \mu \mathrm{M}$ ethylenediamine di(o-hydroxyphenylactic acid [EDDHA]) arranged as a randomized complete block design with 10 replications.

$x$ Values describe the mean disease rating per plant as determined from a disease rating scale from 1 ( 0 to $1 \%$ necrotic leaf area) to 8 (75 to $100 \%$ necrotic leaf area) (45). Means followed by the same letter are not significantly different $(P=0.05)$ and were compared using single-degreeof-freedom contrasts. The experiment was repeated six times. Data are from a representative experiment.

y Cucumber plants were grown in a potting mix that was not amended with an iron chelator.

${ }^{\mathrm{z}}$ Cucumber plants were grown in potting mix that was drenched twice weekly with $10 \mu \mathrm{M}$ EDDHA solution to lower the concentration of available iron in the rhizosphere. 
biosynthesis pathway. Genomic DNA adjacent to the opposite side of the mini-Tn5-phoA insertion was also similar to the enterobactin biosynthesis gene cluster of Escherichia coli. A 698-bp region located $283 \mathrm{bp}$ from the mini-Tn5-phoA insertion exhibited nucleotide similarity to a number of homologs of entC, which encodes isochorismate synthase, another enterobactin biosynthetic enzyme. These data provide convincing evidence that the miniTn5-phoA insertion is in the catechol siderophore biosynthesis gene cluster of Serratia marcescens.

A 2-kb PstI-EcoRI fragment containing the wild-type entC-entA region of strain 90-166 was subcloned from a cosmid that hybridized to DNA adjacent to the mini-Tn5-phoA insertion of mutant 90-166-2882. Sequence analysis indicated the presence of entC upstream of entA, with a 284-bp intergenic region separating the two genes. entC of Serratia marcescens $90-166$ was 956 bp compared with 1,175 bp in Escherichia coli, and the sequences of the homologs were 57 and $31 \%$ identical at the nucleotide and predicted amino acid levels, respectively. Only $617 \mathrm{bp}$ of the $5^{\prime}$ portion of entA was present on the 2 -kb fragment, and the sequence of this was $57 \%$ identical to the corresponding $5^{\prime}$ portion of entA of Escherichia coli at both the nucleotide and predicted amino acid levels. entA contains a characteristic $2 \mathrm{Fe}-2 \mathrm{~S}$ ironsulfur cluster motif present in all known dehydrogenases $(7,19)$, further supporting the role of the entA homologue as the gene encoding 2,3-dihydro-2,3-dihydroxybenzoate dehydrogenase. The organization of the enterobactin gene cluster in Serratia marcescens clearly differs from that published for Escherichia coli $\mathrm{K} 12$ where $e n t A$ and $e n t C$ are separated by entE and $e n t B(8)$. Based on these data, strain $90-166-2882$ is hereafter referred to as an entA mutant of 90-166.

Influence of catechol siderophore production by Serratia marcescens on ISR. Severity of anthracnose was reduced in plants induced by prior inoculation with the pathogen $C$. orbiculare or in plants induced by inoculation with Serratia marcescens 90-166. In contrast, disease severity of cucumbers treated with 90-166-2882 (entA) was not significantly different $(P=0.05)$ from the disease control (plants inoculated with the pathogen only) (Table 3).

Root colonization assays. The population sizes of wild-type strain 90-166 and entA mutant 90-166-2882 were compared in order to determine if lack of ISR could be attributed to a reduction in root population size of the entA derivative. Total (internal plus external) population sizes of 90-166 and 90-166-2882 on roots did not differ significantly $(P=0.05)$ at any sample times (Fig. 1A). Internal population sizes of the entA strain were significantly lower $(P=0.05)$ than those of the wild-type strain at two sampling times (Fig. 1B). Internal population sizes of 90-166 were 7.42 and $2.97 \log$ (CFU per gram) at 4 and 10 DAP, respectively, compared with 90-166-2882 populations, which were 6.27 and $2.56 \log$ (CFU per gram) on those days. There was no significant difference between population sizes of the strains at 8 DAP.

TABLE 3. Effect of Serratia marcescens strain 90-166 and its catechol siderophore deficient $\left(\mathrm{Cat}^{-}\right)$mutant on anthracnose of cucumber caused by Colletotrichum orbiculare

\begin{tabular}{lc}
\hline Treatment $^{y}$ & Mean disease rating $^{z}$ \\
\hline Disease control & 8.00 \\
SAR control & $7.04^{*}$ \\
$90-166$ wild type & $7.57^{*}$ \\
$90-166-2882$ Cat $^{-}$ & 7.97 \\
\hline
\end{tabular}

y Cucumber seeds were soaked in $0.14 \mathrm{M} \mathrm{NaCl}$ (nonbacterized [disease] control and (systemic acquired resistance [SAR; pathogen-induced] control), or bacterial suspensions ( $10 \log \mathrm{CFU} / \mathrm{ml})$.

${ }^{\mathrm{z}}$ Data are means of four experiments combined after performing Bartlett's test for homogeneity of variance $\left(\chi^{2}=30.0 ; \alpha=0.000001\right)$. * Indicates a significant reduction in disease compared with the disease control at $P \leq$ 0.05 using single-degree-of-freedom contrasts.

\section{DISCUSSION}

The level of ISR mediated by Serratia marcescens strain 90-166 varied with iron concentration of the potting mix in which cucumber was grown. ISR mediated by strain 90-166 was improved significantly when external iron availability to the host plant was reduced through addition of iron chelator EDDHA. These results complement those of an earlier study demonstrating that ISR by strain $90-166$ is reduced significantly when iron availability is increased (34). Together, these studies indicate that 90-166-mediated ISR is dependent on iron concentration. These observations agree with those reported by Leeman et al. (22); in that study, treatment of radish with $P$. putida strain WCS358 did not result in ISR under conditions of high iron availability. Similarly, another rhizobacterial strain, P. fluorescens WCS374, was more effective in suppressing disease through ISR under conditions of low iron availability (22).

ISR by strain $90-166$ was affected by external iron concentration, indicating that iron-regulated production of components such as siderophores might be important in ISR by this strain. Bacteria commonly produce siderophores (iron-chelating agents) in response to iron deficit during their growth $(6,49)$, and siderophores can contribute to biological control of certain soilborne plant pathogens $(2,20)$. A mutagenesis approach was employed to
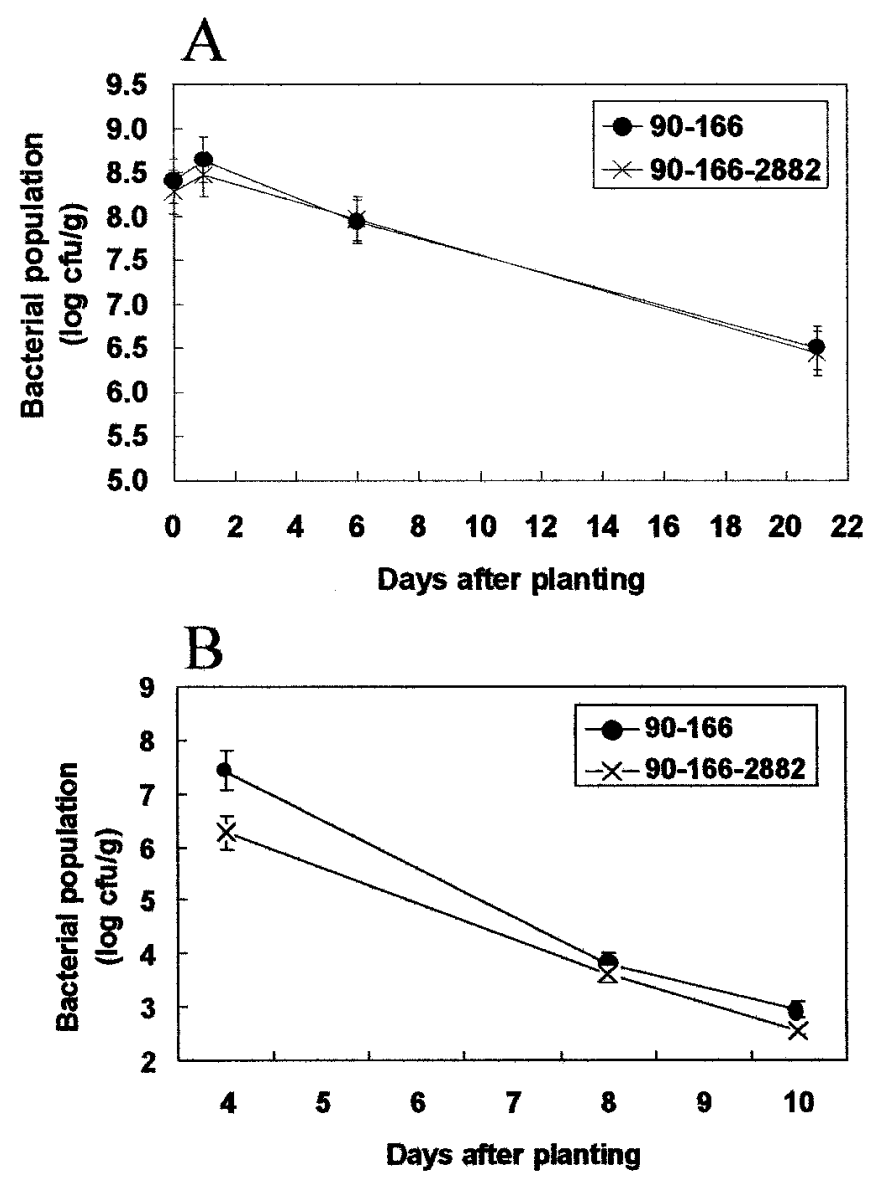

Fig. 1. Population sizes of Serratia marcescens 90-166 (•) and the ent $A^{-}$ mutant 90-166-2882 (×) on cucumber. A, Total root population sizes were determined by triturating roots in $0.02 \mathrm{M}$ phosphate buffer and plating on tryptic soy agar amended with either $100 \mu \mathrm{g} / \mathrm{ml}$ of ampicillin (for 90-166) or ampicillin and $50 \mu \mathrm{g} / \mathrm{ml}$ of kanamycin (for 90-166-2882). The experiment was a $2 \times 5$ ( 2 bacterial treatments [90-166 or 90-166-2882] and 5 sample times; $0,1,4,7$, and 21 days after planting [DAP]) factorial arranged in a random complete block design (RCBD) with seven replications. B, Internal root population sizes were determined by triturating surface-disinfested roots as described previously. The experiment was a $2 \times 3$ (2 bacterial treatments [90-166 or 90-166-2882] and 3 sample times; 4, 8, and 10 DAP) factorial arranged in a RCBD with seven replications. 
evaluate the role of siderophore production by $90-166$ in ISR. One mutant (90-166-2882) lacking catechol siderophore production had a transposon insertion in an entA homolog. Based on known pathways of enterobactin production in Escherichia coli $(18,39)$, a disruption of entA would predict a loss of 2,3-dihydro-2,3dihydroxybenzoate dehydrogenase activity and the inability to form the product 2,3-DHBA. This prediction is supported by the result that 90-166-2882 did not cross-feed mutants (enb-7, AN193) that were deficient in 2,3-DHBA production. Because the DNA flanking the insertion site was homologous to several other genes involved in iron acquisition in different bacterial species (entC, and its homologues $d h b C$, pmsC, and amoA; entA and its homologue $d h b A$ ), it is likely that this genetic region also functions in catechol production in 90-166.

The entA mutant 90-166-2882 no longer induced resistance in cucumber to $C$. orbiculare supporting the hypothesis that the catechol siderophore produced by the wild-type strain 90-166 is necessary for ISR. A role for siderophores in ISR was also reported by Maurhofer et al. (28) who observed that a pyoverdindeficient strain of $P$. fluorescens CHA0 (CHA400) no longer induced resistance against Tobacco necrosis virus in tobacco. Clearly, siderophores are only one determinant of bacterialmediated ISR, because pyoverdin-deficient mutants of $P$. putida WCS374 retain their capacity to induce resistance at high iron concentrations (22) and other factors, such as lipopolysaccharide or SA, can contribute to ISR. For Serratia marcescens 90-166, however, the entA mutant that does not induce resistance retains SA production, indicating that catechol rather than SA is required for ISR. Taken together, results from various studies suggest that siderophores differ in their influence on plant resistance responses or that some bacterial strains have additional characteristics involved in ISR that can compensate for lack of siderophore production.

The loss of ISR capacity by mutant strain 90-166-2882 is unlikely to be attributable to lack of rhizosphere colonization, because total root population sizes of the entA mutant and its parental strain were similar. These results agree with those of many other scientists who have observed that siderophoredeficient mutants establish rhizosphere population sizes similar to those of parental siderophore-producing strains $(10,11,28)$. In our experiments, there was a significant decrease $(P=0.05)$ in internal root population sizes of 90-166-2882 compared with wildtype strain 90-166 (Fig. 1B) at two sample times. It remains to be determined whether changes in internal colonization by the entA mutant contributed to changes in the ISR phenotype of this strain. It is possible that siderophore production by strain 90-166 serves to detoxify the active oxygen species (AOS) produced by the plant in response to the bacterium as was reported for Erwinia amylovora siderophores (12). The lack of enterobactin production by 90-166-2882 may render this strain more susceptible to AOS and result in lowered internal populations.

In conclusion, the reduction in disease severity associated with rhizobacterial treatment under conditions of reduced iron concentration and the lack of ISR by the ent $A^{-}$mutant disrupted in catechol-siderophore biosynthetic genes support the hypothesis that a catechol siderophore produced by 90-166 under iron limited conditions in vivo contributes to ISR. Future experiments evaluating the influence of iron on production of bacterial determinants necessary for ISR and the activity of the ferric-catechol complex on plant disease resistance promise to further develop an understanding of iron in plant-microbe interactions.

\section{ACKNOWLEDGMENTS}

Funding was provided, in part, by the U.S. Department of Agriculture CSREES NRI (Grant No. 9802873). We thank W. Kissalita, University of Georgia, for the isolation of siderophore fractions of 90-166, and M. Wilson and W. Mahaffee for critical reviews of this manuscript.

\section{LITERATURE CITED}

1. Adams, R., and Schumann, W. 1993. Cloning and mapping of the Bacillus subtilis locus homologous to Escherichia coli ent genes. Gene 133:119-121.

2. Ahl, P., Voisard, C., and Defago, G. 1986. Iron bound-siderophores, cyanic acid and antibiotics involved in suppression of Thielaviopsis basicola by a Pseudomonas fluorescens strain. J. Phytopathol. 116:121-134.

3. Alström, S. 1991. Induction of disease resistance in common bean susceptible to halo blight bacterial pathogen after seed bacterization with rhizosphere pseudomonads. J. Gen. Appl. Microbiol. 37:495-501.

4. Angerer, A., Klupp, B., and Braun, V. 1992. Iron transport systems of Serratia marcescens. J. Bacteriol. 174:1378-1387.

5. Ausubel, F. M., Brent, R., Kingston, R. E., Moore, D. D., Seidman, J. G., Smith, J. A., and Struhl, K. 1998. Current Protocols in Molecular Biology, Vol. 1. John Wiley \& Sons, New York.

6. Barton, L. L., and Hemming, B. C. 1993. Iron Chelation in Plants and Soil Microorganisms. Academic Press, San Diego, CA.

7. Beinert, H. 1990. Recent developments in the field of iron-sulfur proteins. FASEB J. 4:2483-2491.

8. Blattner, F. R., Plunkett, G., III, Bloch, C. A., Perna, N. T., Burland, V., Riley, M., Collado-Vides, J., Glasner, J. D., Rode, C. K., Mayhew, G. F., Gregor, J., Davis, N. W., Kirkpatrick, H. A., Goeden, M. A., Rose, D. J., Mau, B., and Shao, Y. 1997. The complete genome sequence of Escherichia coli K-12. Science 277:1453-1474.

9. Bull, C. T., Ishimaru, C. A., and Loper, J. E. 1994. Two genomic regions involved in catechol siderophore production by Erwinia carotovora. Appl. Environ. Microbiol. 60:662-669.

10. Buysens, S., Heungens, K., Poppe, J., and Höfte, M. 1996. Involvement of pyochelin and pyoverdin in suppression of Pythium-induced dampingoff of tomato by Pseudomonas aeruginosa 7NSK2. Appl. Environ. Microbiol. 62:865-871.

11. Costa, J. M., and Loper, J. E. 1994. Characterization of siderophore production by the biological control agent Enterobacter cloacae. Mol. Plant-Microbe Interact. 7:440-448.

12. Dellagi, A., Brisset, M.-N., Paulin, J.-P., and Expert, D. 1998. Dual role of desferrioxamine in Erwinia amylovora pathogenicity. Mol. PlantMicrobe Interact. 11:734-742.

13. de Lorenzo, V., Herrero, M., Jakubzik, U., and Timmis, K. N. 1990. Mini-Tn5 transposon derivatives for insertion mutagenesis, promoter probing, and chromosomal insertion of cloned DNA in Gram-negative eubacteria. J. Bacteriol. 172:6568-6572.

14. De Meyer, G., and Höfte, M. 1997. Salicylic acid produced by the rhizobacterium Pseudomonas aeruginosa 7NSK2 induces resistance to leaf infection by Botrytis cinerea on bean. Phytopathology 87:588-593.

15. Duijff, B. J., Bakker, P. A. H. M., and Schipper, B. 1994. Suppression of Fusarium wilt of carnation by Pseudomonas putida WCS358 at different levels of disease incidence and iron availability. Biocontrol Sci. Technol. 4:279-288.

16. Elkins, M. F., and Earhart, C. F. 1988. An Escherichia coli enterobactin cluster gene with sequence homology to $\operatorname{trpE}$ and $p a b B$. FEMS Microbiol. Lett. 56:35-40

17. Goode, M. J. 1958. Physiological specialization in Colletotrichum lagenarium. Phytopathology 48:79-83.

18. Grossman, T. H., Tuckman, M., Ellestad, S., and Osburne, M. S. 1993. Isolation and characterization of Bacillus subtilis genes involved in siderophore biosynthesis: Relationship between B. subtilis sfp and Escherichia coli entD genes. J. Bacteriol. 175:6203-6211.

19. Johnson, M. K. 1994. Iron-sulfur proteins. Pages 1895-1915 in: Encyclopedia of Inorganic Chemistry. R. B. King, ed. Wiley, Chichester, England.

20. Kloepper, J. W., Leong, J., Teintze, M., and Schroth, M. N. 1980. Enhanced plant growth by siderophores produced by plant growthpromoting rhizobacteria. Nature 286:885-886.

21. Langman, L., Young, I. G., Frost, G. E., Rosenberg, H., and Gibson, F. 1972. Enterochelin system of iron transport in Escherichia coli: Mutations affecting ferric-enterochelin esterase. J. Bacteriol. 112:1142-1149.

22. Leeman, M., den Ouden, F. M., van Pelt, J. A., Dirkx, F. P. M., Steijl, H., Bakker, P. A. H. M., and Schippers, B. 1996. Iron availability affects induction of systemic resistance to fusarium wilt of radish by Pseudomonas fluorescens. Phytopathology 86:149-155.

23. Leeman, M., Van Pelt, J. A., Den Ouden, F. M., Heinsbroek, M., Bakker, P. A. H. M., and Schippers, B. 1995. Induction of systemic resistance against fusarium wilt of radish by lipopolysaccharides of Pseudomonas fluorescens. Phytopathology 85:1021-1027.

24. Liss, L. 1987. New M13 host: DH5 $\alpha$ F' competent cells. Focus 9:13.

25. Litwin, C. M., Rayback, T. W., and Skinner, J. 1996. Role of catechol siderophore synthesis in Vibrio vulnificus virulence. Infect. Immun. 64:2834-2838.

26. Liu, J., Duncan, K., and Walsh, C. T. 1989. Nucleotide sequence of a 
cluster of Escherichia coli enterobactin biosynthesis genes: Identification of entA and purification of its product 2,3-dihydro-w,3dihydroxybenzoate dehydrogenase. J. Bacteriol. 171:791-798.

27. Liu, J., Quinn, N., Berchtold, G. A., and Walsh, C. T. 1990. Overexpression, purification, and characterization of isochorismate synthase (EntC), the first enzyme involved in the biosynthesis of enterobactin from chorismate. Biochem. 29:1417-1425.

28. Maurhofer, M., Hase, C., Meuwly, P., Métraux, J.-P., and Défago, G. 1994. Induction of systemic resistance of tobacco to tobacco necrosis virus by the root-colonizing Pseudomonas fluorescens strain CHA0: Influence of the gacA gene and of pyoverdine production. Phytopathology 84:139-146.

29. Nahlik, M. S., Brickman, T. J., Ozenberger, B. A., and McIntosh, M. A. 1989. Nucleotide sequence and transcriptional organization of the Escherichia coli enterobactin biosynthesis cistrons entB and entA. J. Bacteriol. 171:784-790.

30. Nahlik, M. S., Fleming, T. P., and McIntosh, M. A. 1987. Cluster of genes controlling synthesis and activation of 2,3-dihydroxybenzoic acid in production of enterobactin in Escherichia coli. J. Bacteriol. 169: 4163-4170.

31. Pickett., C. L., Hayes, L., and Earhart, C. F. 1984. Molecular cloning of the Escherichia coli K-12 entACGBE genes. FEMS Microbiol. Lett. 24:77-80.

32. Pollack, J. R., Ames, B. N., and Neilands, J. B. 1970. Iron transport in Salmonella typhimurium mutants blocked in the biosynthesis of enterobactin. J. Bacteriol. 104:635-639.

33. Press, C. M., and Kloepper, J. W. 1997. Role of bacterial cell constituents in PGPR-mediated induced systemic resistance of cucumber. Pages 260-264 in: Plant Growth-Promoting Rhizobacteria, Present Status and Future Prospects. A. Ogoshi, K. Kobayashi, Y. Homma, F. Kodama, N. Kondo, and S. Akino, eds. Proc. Int. Workshop Plant Growth-Promoting Rhizobacteria, 4th. Japan-OECD Joint Workshop. Nakanishi Printing, Sapporo, Japan.

34. Press, C. M., Wilson, M., Tuzun, S., and Kloepper, J. W. 1997. Salicylic acid produced by Serratia marcescens $90-166$ is not the primary determinant of induced systemic resistance in cucumber or tobacco. Mol. Plant-Microbe Interact. 10:761-768.

35. Rioux, C., Jordan, D. C., and Rattray, J. B. M. 1983. Colorimetric determination of catechol siderophores in microbial cultures. Anal. Biochem. 133:163-169.

36. Rowland, B. M., Grossman, T. H., Osburne, M. S., and Taber, H. W. 1996. Sequence and genetic organization of a Bacillus subtilis operon encoding 2,3-dihydroxybenzoate biosynthetic enzymes. Gene 178:119-123.

37. Rusnak, F., Liu, J., Quinn, N., Berchtold, G. A., and Walsh, C. T. 1990. Sub-cloning of the enterobactin biosynthetic gene entB: Expression, purification, characterization, and substrate specificity of isochoris- matase. Biochemistry 29:1425-1435.

38. Rusnak, F., Sakaitani, M., Brueckhammer, D., Reichert, J., and Walsh, C. T. 1991. Biosynthesis of the Escherichia coli siderophore enterobactin: Sequence of the entF gene, expression and purification of Ent F, and analysis of covalent phosphopantetheine. Biochemistry 30:2916-2927.

39. Sakaitani, M., Rusnak, F., Quinn, N. R., Tu, C., Frigo, T. B., Berchtold, G. A., and Walsh, C. T. 1990. Mechanistic studies on trans-2,3-dihydro2,3-dihydroxybenzoate dehydrogenase (Ent A) in the biosynthesis of the iron chelator enterobactin. Biochemistry 29:6789-6798.

40. Sambrook, J., Fritsch, E. F., and Maniatis, T. 1989. Molecular Cloning: A Laboratory Manual, 2nd ed. Cold Spring Harbor Laboratory, Cold Spring Harbor, NY.

41. Schmidt, M. P., and Payne, S. M. 1991. Genetic analysis of the enterobactin gene cluster in Shigella flexneri. J. Bacteriol. 173:816-825.

42. Schwyn, B., and Neilands, J. B. 1987. Universal chemical assay for the detection and determination of siderophores. Anal. Biochem. 160:47-56.

43. Serino, L., Reimmann, C., Baur, H., Beyeler, M., Visca, P., and Haas, D. 1995. Structural genes from salicylate biosynthesis from chorismate in Pseudomonas aeruginosa. Mol. Gen. Genet. 249:217-228.

44. Simon, E. H., and Tessman, I. 1963. Thymidine-requiring mutants of phage T4. PNAS 50:526-532.

45. Thompson, D. C., and Jenkins, S. F. 1985. Pictorial assessment key to determine fungicide concentrations that control anthracnose development on cucumber cultivars with varying resistance levels. Plant Dis. 69:833-836.

46. van Peer, R., Niemann, G. J., and Schippers, B. 1991. Induced resistance and phytoalexin accumulation in biological control of Fusarium wilt of carnation by Pseudomonas sp. strain WCS417r. Phytopathology 81: 728-734.

47. Wayne, R., Frick, K., and Neilands, J. B. 1976. Siderophore protection against colicins M, B, V, and Ia in Escherichia coli. J. Bacteriol. 126:7-12.

48. Wei, G., Kloepper, J. W., and Tuzun, S. 1991. Induction of systemic resistance of cucumber to Colletotrichum orbiculare by select strains of plant growth-promoting rhizobacteria. Phytopathology 81:1508-1512.

49. Winkelmann, G. 1991. CRC Handbook of Microbial Iron Chelates. CRC Press, Boca Raton, FL.

50. Wyckoff, E. E., Stoebner, J. A., Reed, K. E., and Payne, S. M. 1997. Cloning of a Vibrio cholerae vibriobactin gene cluster: Identification of genes required for early steps in siderophore biosynthesis. J. Bacteriol. 179:7055-7062.

51. Yanisch-Perron, C., Viera, J., and Messing, J. 1985. Improved M13 phage cloning vectors and host strains: Nucleotide sequences of the M13mp18 and pUC19 vectors. Gene 33:103-119.

52. Zimmermann, L., Angerer, A., and Braun, V. 1989. Mechanistically novel iron (III) transport system in Serratia marcescens. J. Bacteriol. 171:238-243. 